\title{
Membrane mesothelin expression positivity is associated with poor clinical outcome of luminal-type breast cancer
}

\author{
TAKAFUMI SUZUKI $^{1 *}$, YOJI YAMAGISHI $^{1,2^{*}}$, TAKAHIRO EINAMA $^{1}$, TOMOMI KOIWAI $^{1}$, \\ TAMIO YAMASAKI $^{1}$, MAKIKO FUKUMURA-KOGA ${ }^{1}$, YUSUKE ISHIBASHI ${ }^{1}$, YASUHIRO TAKIHATA ${ }^{1}$, \\ TAKEHIRO SHIRAISHI ${ }^{1}$, YOICHI MIYATA ${ }^{1}$, TOSHIMITSU IWASAKI ${ }^{1}$, EIJI SHINTO ${ }^{1}$, \\ KIMIYA SATO $^{2}$, HIDEKI UENO ${ }^{1}$, JUNJI YAMAMOTO ${ }^{1}$, YOJI KISHI ${ }^{1}$ and HITOSHI TSUDA ${ }^{2}$
}

Departments of ${ }^{1}$ Surgery and ${ }^{2}$ Basic Pathology, National Defense Medical College, Tokorozawa, Saitama 359-8513, Japan

Received May 8, 2020; Accepted August 4, 2020

DOI: $10.3892 / 01.2020 .12055$

\begin{abstract}
Mesothelin is expressed in various types of malignant tumors. The present study immunohistochemically investigated mesothelin expression and its clinicopathological significance in each subtype of breast cancer, with special reference to its cellular localization, in particular, membrane mesothelin expression. Using tissue specimens from 482 patients with breast cancer, immunohistochemistry was used to study mesothelin expression and help classify its localization as membrane or cytoplasmic expression. Mesothelin expression was detected in 77 (16.0\%) cases and was the highest in triple-negative breast cancer $(31 / 75 ; 41.3 \%)$, followed by human epithelial growth factor receptor type 2 type $(6 / 33,18.2 \%)$ and luminal type $(36 / 374 ; 9.6 \%)$. Among the 482 cases, membrane mesothelin expression was detected in 73 cases and was significantly associated with a negative hormone receptor status, higher Ki-67 labeling index, nuclear grade 3 and a lower relapse-free survival rate. Cytoplasmic mesothelin expression was not significantly associated with a lower relapse-free survival rate $(\mathrm{P}=0.058)$. In the 343 cases of luminal type, the membrane mesothelin expression-positive
\end{abstract}

Correspondence to: Dr Takahiro Einama, Department of Surgery, National Defense Medical College, 3-2 Namiki, Tokorozawa, Saitama 359-8513, Japan

E-mail: einama0722@ndmc.ac.jp

${ }^{*}$ Contributed equally

Abbreviations: CAR, chimeric antibody receptor; CME, cytoplasmic mesothelin expression; CTL, cytotoxic T lymphocytes; ER, estrogen receptor; FISH, fluorescence in situ hybridization; HER2, human epithelial growth factor receptor type 2; IHC, immunohistochemically; LI, labeling index; Ly, lymphatic invasion; ME, mesothelin expression; MME, membrane mesothelin expression; NG, nuclear grade; OS, overall survival; $\mathrm{PgR}$, progesterone receptor; RFS, relapse-free survival; TNBCs, triple-negative breast cancers; V, vascular invasion

Key words: breast cancer, mesothelin, membrane, luminal type, triple-negative breast cancers group had significantly worse prognosis than the membrane mesothelin-expression-negative group $(\mathrm{P}=0.042)$. There was no significant difference in the relapse-free survival rate according to the membrane mesothelin expression status in the triple-negative type and other types. It was suggested that membrane mesothelin expression in luminal type breast cancer is associated with a lower rate of relapse-free survival.

\section{Introduction}

Mesothelin is a $40-\mathrm{kDa}$ cell surface glycoprotein that is expressed on normal mesothelial cells that line the pleura, pericardium, and peritoneum (1). Mesothelin is overexpressed in various types of malignant tumors, including malignant mesothelioma, ovarian cancer, and pancreatic cancer (2-4). The full-length human mesothelin gene encodes a 71-kDa precursor protein, which can be physiologically cleaved by some fern-like proteases into a membrane-bound $40-\mathrm{kDa}$ C-terminal fragment and a $31-\mathrm{kDa} \mathrm{N}$-terminal fragment, which is secreted into the blood (5). The 40-kDa C-terminal fragment, mesothelin, is attached to the cell membrane through a glycosyl-phosphatidylinositol anchor $(5,6)$.

The biological functions of mesothelin are unclear, although recent studies have suggested that overexpression of mesothelin increases cell proliferation and migration (7). Furthermore, positive mesothelin expression (ME) is associated with an unfavorable prognosis in pancreatic cancer, gastric cancer, and colorectal cancer (4,8-10).

The number of studies on ME in breast cancer is limited. Wang et al (11) suggested that the ME level in invasive breast cancer tissue was inversely correlated with overall survival (OS). Furthermore, based on subtype classification, Parinyanitikul et al (12) and Bayoglu et al (13) showed that mesothelin was overexpressed in most triple-negative breast cancers (TNBCs), but was not correlated with survival outcomes in TNBC. Tchou et al (14) demonstrated that ME-positivity was rare and was not correlated with patient outcome in estrogen receptor (ER)-positive or human epithelial growth factor receptor type 2 (HER2)-positive breast cancers. Moreover, Einama et al (9) reported that the localization of ME was related to OS in gastric cancer. To the best of our knowledge, there have been no previous studies on the 
relationship between the cellular localization of mesothelin and the prognosis of breast cancer patients.

In this study, we investigated ME in each subtype of breast cancer using immunohistology, with special reference to its cellular localization, and analyzed its clinicopathological significance, including patient outcome.

\section{Materials and methods}

Ethics approval and consent to participate. This study was performed in accordance with the Declaration of Helsinki and was approved by the Institutional Review Board of the National Defense Medical College (registration no. 3003). All patients agreed to participate in this study, and written informed consent was obtained from all patients.

Patients. The subjects of this study comprised 482 patients who underwent radical surgery for primary breast cancer between 2002 and 2013. Patients with stage IV and non-primary breast cancer were excluded. The ER and progesterone receptor $(\mathrm{PgR})$ statuses of the tumor were assessed using immunohistochemistry and defined as positive if $1 \%$ or more of the constituent carcinoma cells were immunoreactive. The HER2 status of the tumor was evaluated immunohistochemically (IHC), and fluorescence in situ hybridization (FISH) was performed in cases with a score of $2+$. HER2 was considered positive when the IHC score was 3+ or FISH was positive according to the 2013 American Society of Clinical Oncology/College of American Pathologists guidelines. The nuclear grade (NG) was determined by the sum of the nuclear atypia score and the mitosis count score (15). Ki-67 was evaluated according to the recommendation of the Breast Cancer Working Group (16), and the Ki-67 labeling index (LI) was defined as high if 14\% or more of the constituent carcinoma cells were immunoreactive (17). Breast cancers were classified into four subtypes according to the St. Gallen consensus as follows (18): Luminal type, ER+ and/or PgR+/HER2-; luminal HER2 type, ER+ and/or PgR+/HER2+; HER2 type, ER-/PgR-/HER2+; TNBC type, ER-/PgR-/HER2-.

Immunohistochemistry. Tissue microarrays of 482 breast cancer patients were used in this study. Sections with a thickness of $4 \mu \mathrm{m}$ were cut from formalin-fixed paraffin-embedded tissue blocks and mounted on charged glass slides, deparaffinized, and rehydrated through a graded ethanol series. For antigen retrieval, a target retrieval solution at $\mathrm{pH} 9.0$ (catalogue number, S2368; Dako Japan) was used, and the slides were boiled in a pressure cooker (Pascal Pressure Cooker, Model: S2800; Dako) at $125^{\circ} \mathrm{C}$ for $3 \mathrm{~min}$. Endogenous peroxidase was blocked with $0.3 \%$ hydrogen peroxidase. The slides were incubated with a 1:50 dilution of a mouse monoclonal antibody in mesothelin (clone 5B2, diluted 1:50; Novocastra) at room temperature for $30 \mathrm{~min}$, and then reacted with a dextran polymer reagent combined with secondary antibodies and peroxidase (Envision/HRP; Dako) for $30 \mathrm{~min}$ at room temperature. Specific antigen-antibody reactions were visualized with $0.2 \%$ diaminobenzidine tetrahydrochloride and hydrogen peroxide. Slides were counterstained with hematoxylin for $10 \mathrm{~min}$ and then rinsed gently in reagent quality water.

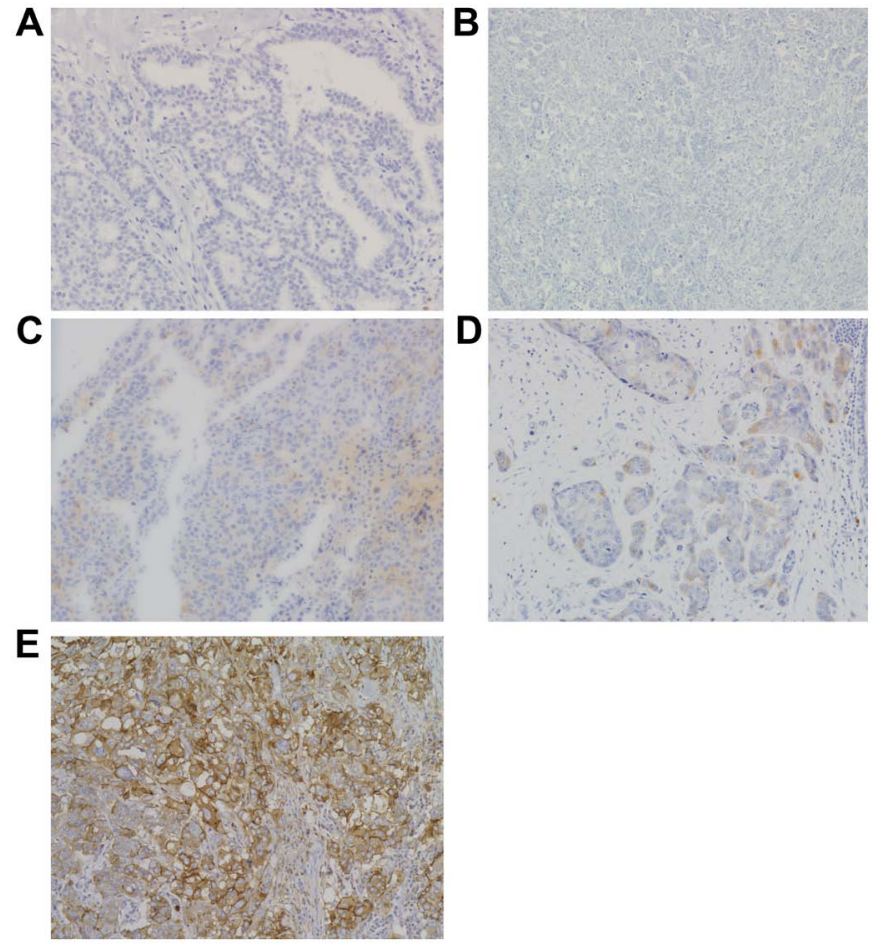

Figure 1. Variations in mesothelin expression and its cellular localization in breast cancer. Immunohistochemical staining for mesothelin. Magnification, $\mathrm{x} 200$. (A) No mesothelin staining in the normal breast tissue. (B) No mesothelin expression in breast cancer. (C) Scant cytoplasmic staining of mesothelin (1+). No mesothelin expression in the membrane. (D) Incomplete mesothelin expression in the membrane (1+) and in the cytoplasm with granular staining (2+). (E) Mesothelin expression in the membrane (2+) and cytoplasm (2+).

Immunohistochemical evaluation. All assessments were made on the tumor region of the specimen (x200). Each slide was independently evaluated by two observers who were blinded to the clinical outcomes (Y.Y. and T.E.). Immunostaining for mesothelin was evaluated for both the proportion and staining intensity of tumor cells in each case. The proportion of ME-positive cancer cells was assessed as 1-10\%,>10-50\%, and $>50 \%$. The staining intensity was evaluated as weak $(+1)$ or moderate to strong (+2). The staining proportion and intensity were judged separately between the membrane and cytoplasm (Fig. 1). No mesothelin staining was observed in the normal breast tissue. ME was defined as positive when the percentage of positive cells was $\geq 1 \%$ of the tumor cells, regardless of the intensity. Furthermore, among the ME-positive cases, the staining localization of mesothelin was evaluated as membrane, cytoplasm, or both. When the entire circumference of the membrane was evenly or partially stained throughout the whole section, 'membrane mesothelin expression (MME)' was defined as positive. When cytoplasmic staining, including cytoplasmic granular staining, was clearly observed in $\geq 1 \%$ of the tumor cells, 'cytoplasmic mesothelin expression (CME)' was defined as positive.

Statistical analysis. The $\chi^{2}$ test or Fisher's exact test were used to determine the correlation between ME and clinicopathological parameters. Survival curves were drawn using the Kaplan-Meier method, and compared using the log-rank test. The prognostic implications of these parameters were analyzed using Cox's univariate and multivariate proportional 


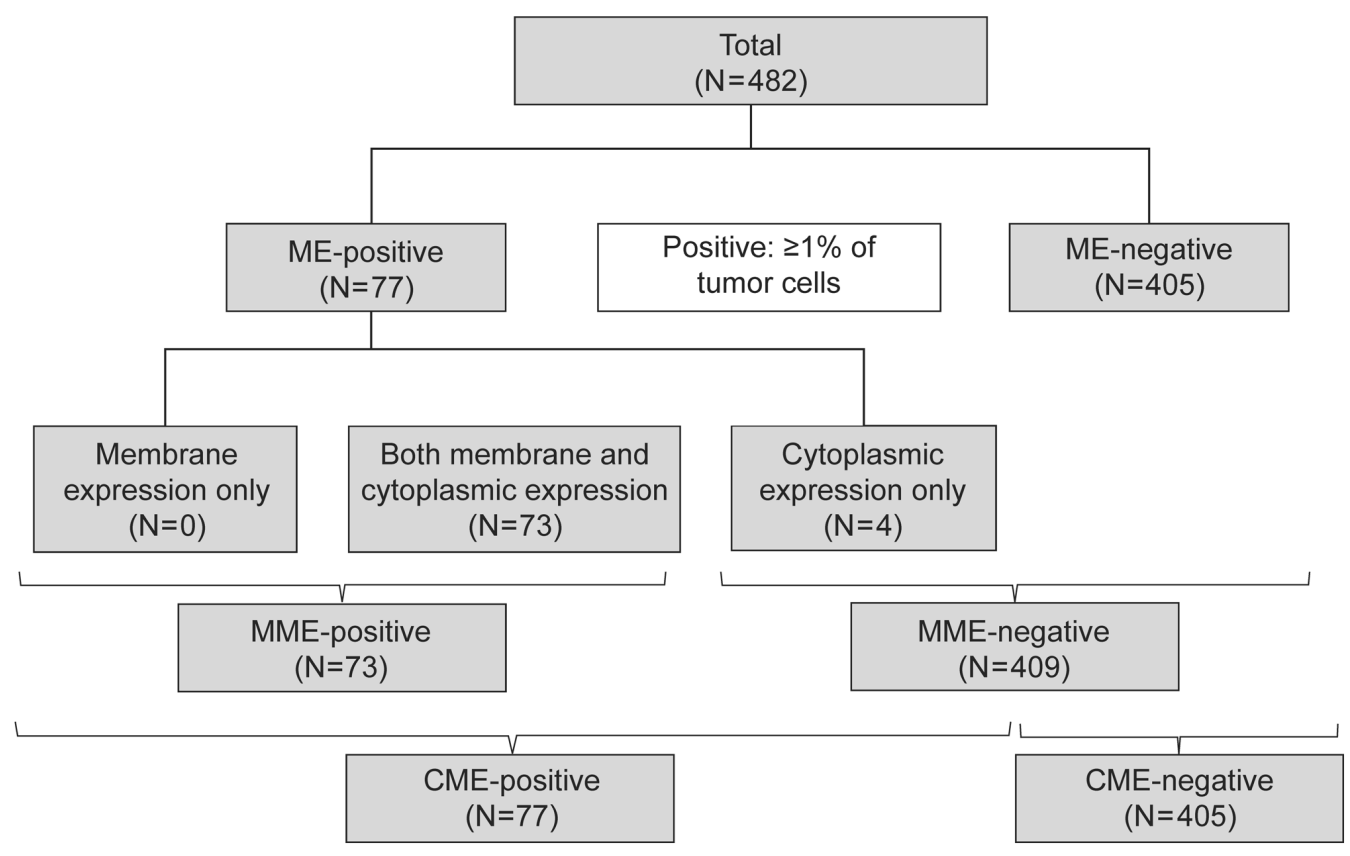

Figure 2. Flow chart for the evaluation of ME. CME, cytoplasmic mesothelin expression; ME, mesothelin expression; MME, membrane mesothelin expression.

hazards models. All differences were considered significant at a P-value <0.05. Statistical analyses were performed using $\mathrm{JMP}^{\circledR} 14$ (SAS Institute Inc.).

\section{Results}

Clinicopathological analysis of mesothelin expression. Representative membrane and cytoplasmic ME are shown in Fig. 1. Of the 482 breast cancer tissue samples, ME-positivity was detected in 77 cases (16.0\%), MME-positivity in 73, and CME-positivity in 77, which included all 73 MME-positive cases (Fig. 2).

The total clinicopathological demography of patients is shown in Table I. The mean patient age was 59.1 years [ \pm 11.3 standard deviation (SD)]. Total mastectomies were performed on 226 patients $(46.9 \%)$, and partial mastectomies were performed on 256 patients $(53.1 \%)$. Luminal type breast cancer was the most common (71.2\%), followed by TNBC $(15.6 \%)$. Neoadjuvant chemotherapy was administered to 31 patients, while adjuvant chemotherapy was administered to 190 patients (including administration of trastuzumab to 15 patients). Adjuvant endocrine therapy was administered to 311 patients, and postoperative radiation therapy was administered to 209 patients. A total of 70 patients had a relapse of breast cancer, with a median relapse-free survival (RFS) of 7.5 years $( \pm 3.9 \mathrm{SD})$.

The correlation between ME and clinicopathological characteristics is summarized in Table II. ME was not correlated with age, pT, pN, pStage, lymphatic invasion (Ly), or vascular invasion (V). ME-positivity was more frequent in NG 3 cases $(58 / 221,26.2 \%)$ than in NG $1 / 2$ cases $(19 / 261,7.3 \%)(\mathrm{P}<0.001)$, more frequent in ER-negative cases $(43 / 115,37.4 \%)$ than in ER-positive cases $(34 / 367,9.3 \%)(\mathrm{P}<0.001)$, and more frequent in PgR-negative cases $(45 / 139,32.4 \%)$ than in PgR-positive cases $(32 / 343,9.3 \%)(\mathrm{P}<0.001)$. The mean $\mathrm{Ki}-67 \mathrm{LI}$ was also higher in ME-positive cases $(27.6 \% \pm 26.5 \mathrm{SD})$ than in negative cases $(13.4 \% \pm 13.9 \mathrm{SD})(\mathrm{P}<0.001)$, while HER2 positivity was similar between the ME-positive and negative groups. Neoadjuvant chemotherapy had no significant impact on ME positivity $(\mathrm{P}=0.629)$ or other clinicopathological factors, such as Ki-67. Furthermore, in these 31 patients, ME was not associated with the pathological response after neoadjuvant chemotherapy. ME-positivity was the highest in TNBC (44.0\%), followed by HER2 (21.2\%), luminal (10.5\%), and luminal HER2 (3.2\%) subtypes.

Survival analysis associated with mesothelin expression. In analysis of RFS, the MME-positive group had a significantly worse outcome than the MME-negative group $(\mathrm{P}=0.027)$. In contrast, the CME-positive group had a relatively worse RFS than the CME-negative group ( $\mathrm{P}=0.058)$ (Fig. 3). In the analysis of the luminal subtype, the MME-positive group had a significantly worse prognosis than the MME-negative group $(\mathrm{P}=0.034)$. The 5-year RFS rates of the MME-positive and negative groups with luminal subtype were 82.6 and $94.1 \%$, respectively. There were no significant differences in RFS curves between the MME-positive and negative patients in the TNBC subtype and other subtypes. The 5-year RFS rates of the ME-positive and negative groups were 80.7 and $77.5 \%$ with TNBC, and 85.7 and $88.8 \%$ with the other types, respectively (Fig. 4).

In terms of OS, the MME-positive and CME-positive groups had a significantly worse outcome than the corresponding MME-negative and CME-negative groups, respectively ( $\mathrm{P}=0.037$ and $\mathrm{P}=0.028$, respectively) (Fig. 5). There was no significant difference in OS curves between the MME-positive and negative patients in any of the included subtypes. In the analysis of the luminal subtype, the MME-positive group had a relatively worse prognosis than the MME-negative group $(\mathrm{P}=0.068)$.

We performed univariate analyses of all 482 cases using the Cox proportional hazards model and found that $\mathrm{pT}, \mathrm{pN}$, 
Table I. Demographics of 482 patients with breast cancer in the present study.

\begin{tabular}{|c|c|}
\hline Parameter & Value \\
\hline Age, years $($ mean $\pm S D)$ & $59.1 \pm 11.3$ \\
\hline \multicolumn{2}{|l|}{ Surgery, n (\%) } \\
\hline Mastectomy & $226(46.9)$ \\
\hline Partial resection & $256(53.1)$ \\
\hline \multicolumn{2}{|l|}{ pT, n (\%) } \\
\hline Tis & $1(0.2)$ \\
\hline $\mathrm{T} 1$ & $267(55.4)$ \\
\hline $\mathrm{T} 2$ & $195(40.5)$ \\
\hline $\mathrm{T} 3$ & $19(3.9)$ \\
\hline \multicolumn{2}{|l|}{$\mathrm{pN}, \mathrm{n}(\%)$} \\
\hline No & $304(63.1)$ \\
\hline N1 & $124(25.7)$ \\
\hline $\mathrm{N} 2$ & $34(7.1)$ \\
\hline N3 & $20(4.1)$ \\
\hline \multicolumn{2}{|l|}{ Subtype, n (\%) } \\
\hline Luminal HER2- & $343(71.2)$ \\
\hline Luminal HER2+ & $33(6.8)$ \\
\hline HER2 & $31(6.4)$ \\
\hline TNBC & $75(15.6)$ \\
\hline \multicolumn{2}{|c|}{ Neoadjuvant chemotherapy, n (\%) } \\
\hline Yes & $31(6.4)$ \\
\hline No & $451(93.6)$ \\
\hline \multicolumn{2}{|l|}{ Adjuvant therapy, n (\%) } \\
\hline Chemotherapy & $185(38.4)$ \\
\hline Anti-HER2 therapy & $15(3.1)$ \\
\hline Endocrine therapy & $311(64.5)$ \\
\hline Radiation therapy & $209(43.4)$ \\
\hline \multicolumn{2}{|c|}{ Postoperative radiation therapy, $\mathrm{n}(\%)$} \\
\hline Yes & 209 (43.4) \\
\hline No & $273(56.6)$ \\
\hline \multicolumn{2}{|l|}{ Recurrence, n (\%) } \\
\hline Yes & $70(14.5)$ \\
\hline No & $412(85.5)$ \\
\hline \multicolumn{2}{|l|}{ Death, n (\%) } \\
\hline Yes & $51(10.6)$ \\
\hline No & $431(89.4)$ \\
\hline
\end{tabular}

HER2, human epidermal growth factor receptor type 2; SD, standard deviation; TNBC, triple-negative breast cancer.

Ly, V, ER, PgR, Ki-67 LI, NG and MME significantly correlated with the risk of relapse, whereas $\mathrm{CME}$ did not correlate with RFS. Furthermore, in Cox multivariate analysis, pT and $\mathrm{pN}$ were finally chosen as independent prognostic factors for RFS (Table III). In addition, Cox's univariate and multivariate analyses were performed for the 343 luminal type cases (Table IV). Univariate analyses showed that pT, pN, Ly, $\mathrm{V}$ and NG significantly correlated with the risk of relapse, whereas MME had no independent impact $(\mathrm{P}=0.062)$. In
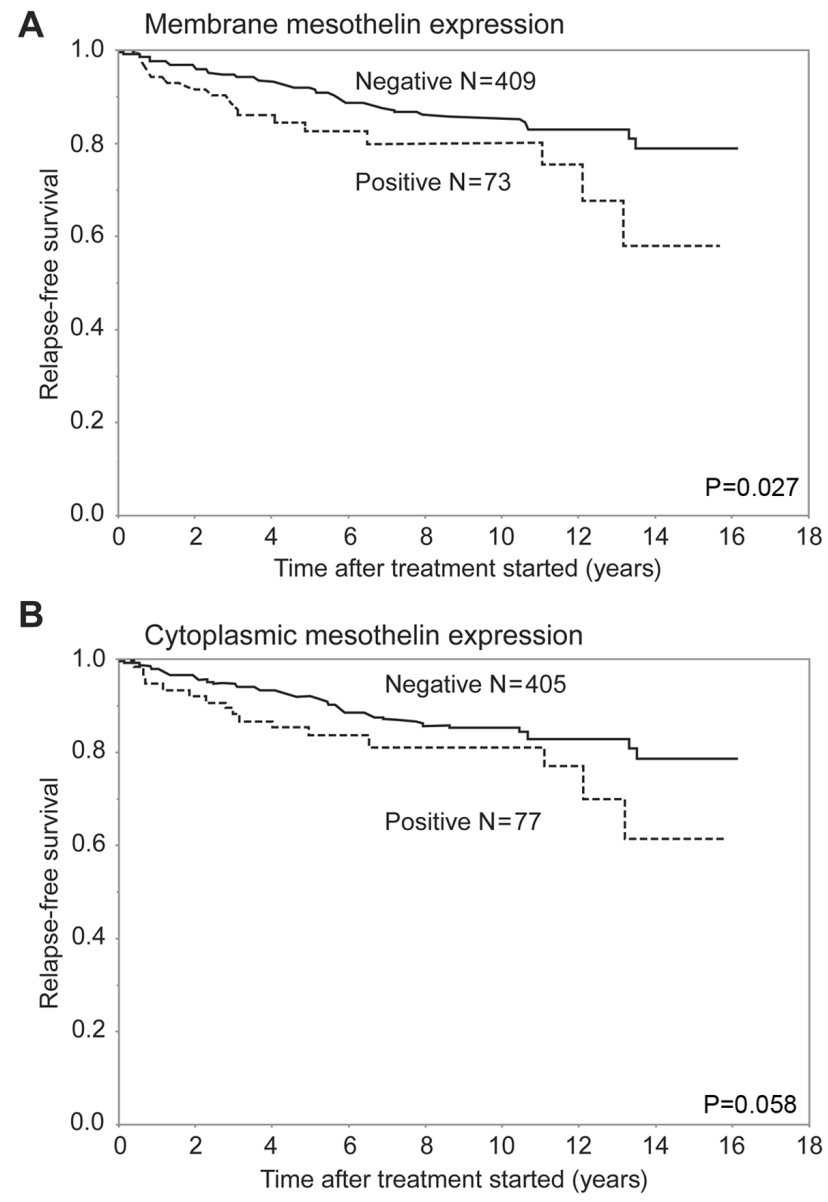

Figure 3. RFS curves for patients with breast cancer after surgical therapy, stratified by mesothelin expression status. (A) Curves for membrane mesothelin expression-positive and -negative groups, and (B) curves for cytoplasmic mesothelin expression-positive and -negative groups. The membrane expression-positive group had a less favorable outcome than the membrane expression-negative group $(\mathrm{P}=0.027)$. However, cytoplasmic mesothelin expression was not significantly associated with RFS $(\mathrm{P}=0.058)$. RFS, relapse-free survival.

multivariate analysis, $\mathrm{pT}$ and $\mathrm{pN}$ were independent prognostic factors for RFS.

\section{Discussion}

In the current study, breast cancer cases were divided into ME-positive and ME-negative groups. In the ME-positive cases, the cellular localization was further divided into MME and CME, and the relationship between ME patterns and clinicopathological factors, including prognosis, was retrospectively investigated. Our results demonstrated that ME was related to conventional prognostic factors, including negative ER, negative PgR, higher Ki-67 LI, and higher NG. Furthermore, we revealed that MME-positivity was associated with lower RFS and OS rates. These results suggest that ME-positivity was an unfavorable prognostic factor in patients with breast cancer, as well as some other cancer types $(4,8-10)$.

In the present study, we showed that MME in the luminal type, but not in other subtypes, was significantly associated with poor RFS. Several previous studies have reported that the ME-positive rates in TNBC were $30-40 \%$, which was in 
Table II. Association between mesothelin expression and clinicopathological parameters in 482 patients with breast cancer.

\begin{tabular}{|c|c|c|c|c|c|c|c|}
\hline \multirow[b]{2}{*}{ Clinicopathological parameters } & \multirow[b]{2}{*}{ Total $(n=482)$} & \multicolumn{2}{|c|}{ MME } & \multirow[b]{2}{*}{ P-value } & \multicolumn{2}{|c|}{ CME } & \multirow[b]{2}{*}{ P-value } \\
\hline & & Positive & Negative & & Positive & Negative & \\
\hline Age, years $(\text { mean } \pm S D)^{\mathrm{a}}$ & & $59.5 \pm 11.5$ & $59.1 \pm 11.3$ & 0.766 & $60.1 \pm 11.5$ & $58.9 \pm 11.3$ & 0.429 \\
\hline \multicolumn{8}{|l|}{$\mathrm{pT}, \mathrm{n}(\%)$} \\
\hline Tis & 1 & $0(0.0)$ & $1(100.0)$ & \multirow[t]{4}{*}{0.071} & $0(0.0)$ & $1(100.0)$ & \multirow[t]{4}{*}{0.071} \\
\hline $\mathrm{T} 1$ & 267 & $32(12.0)$ & $235(88.0)$ & & $34(12.7)$ & $233(87.3)$ & \\
\hline $\mathrm{T} 2$ & 195 & $35(17.9)$ & $160(82.1)$ & & $37(19.0)$ & $158(81.0)$ & \\
\hline $\mathrm{T} 3$ & 19 & $6(31.6)$ & $13(68.4)$ & & $6(31.6)$ & $13(68.4)$ & \\
\hline \multicolumn{8}{|l|}{$\mathrm{pN}, \mathrm{n}(\%)$} \\
\hline No & 304 & $45(14.8)$ & $259(85.2)$ & \multirow[t]{4}{*}{0.433} & $49(16.1)$ & $255(83.9)$ & \multirow[t]{4}{*}{0.464} \\
\hline $\mathrm{N} 1$ & 124 & $16(12.9)$ & $108(87.1)$ & & $16(12.9)$ & $108(87.1)$ & \\
\hline $\mathrm{N} 2$ & 34 & $8(23.5)$ & $26(76.5)$ & & $8(23.5)$ & $26(76.5)$ & \\
\hline N3 & 20 & $4(20.0)$ & $16(80.0)$ & & $4(20.0)$ & $16(80.0)$ & \\
\hline \multicolumn{8}{|l|}{ pStage, n (\%) } \\
\hline 0 & 1 & $0(0.0)$ & $1(100.0)$ & \multirow[t]{4}{*}{0.298} & $0(0.0)$ & $1(100.0)$ & \multirow[t]{4}{*}{0.405} \\
\hline 1 & 204 & $28(13.7)$ & $176(86.3)$ & & $30(14.7)$ & $174(85.3)$ & \\
\hline 2 & 222 & $32(14.4)$ & $190(85.6)$ & & $34(15.3)$ & $188(84.7)$ & \\
\hline 3 & 55 & $13(23.6)$ & $190(76.4)$ & & $13(23.6)$ & $42(76.4)$ & \\
\hline \multicolumn{8}{|l|}{$\mathrm{NG}, \mathrm{n}(\%)$} \\
\hline 1 & 119 & $12(10.1)$ & 107 (89.9) & \multirow[t]{3}{*}{$<0.001$} & $13(10.9)$ & $106(89.1)$ & \multirow[t]{3}{*}{$<0.001$} \\
\hline 2 & 142 & $6(4.2)$ & $136(95.8)$ & & $6(4.2)$ & $136(95.8)$ & \\
\hline 3 & 221 & 55 (24.9) & $166(75.1)$ & & $58(26.2)$ & $163(73.8)$ & \\
\hline \multicolumn{8}{|l|}{ Ly, n (\%) } \\
\hline Negative & 197 & $31(15.7)$ & $166(84.3)$ & \multirow[t]{2}{*}{0.764} & $31(15.7)$ & $166(84.3)$ & \multirow[t]{2}{*}{0.965} \\
\hline Positive & 285 & $42(14.7)$ & $243(85.3)$ & & $46(16.1)$ & 239 (83.9) & \\
\hline $\mathrm{V}, \mathrm{n}(\%)$ & & & & & & & \\
\hline Negative & 312 & $48(15.4)$ & $264(84.6)$ & 0.843 & $51(16.3)$ & $261(83.7)$ & 0.763 \\
\hline Positive & 170 & $25(14.7)$ & $145(85.3)$ & & $26(15.3)$ & 144 (84.7) & \\
\hline ER, n $(\%)$ & & & & & & & \\
\hline Negative & 115 & $40(34.8)$ & $75(65.2)$ & $<0.001$ & $43(37.4)$ & $72(62.6)$ & $<0.001$ \\
\hline Positive & 367 & $33(9.0)$ & $334(91.0)$ & & $34(9.3)$ & 333 (90.7) & \\
\hline PgR, n (\%) & & & & & & & \\
\hline Negative & 154 & $42(27.3)$ & $112(72.7)$ & $<0.001$ & $45(29.2)$ & $109(70.8)$ & $<0.001$ \\
\hline Positive & 328 & $31(9.5)$ & $297(90.5)$ & & $32(9.8)$ & $296(90.2)$ & \\
\hline HER 2, n (\%) & & & & & & & \\
\hline Negative & 418 & $66(15.8)$ & $352(84.2)$ & 0.313 & $69(16.5)$ & $349(83.5)$ & 0.415 \\
\hline Positive & 64 & $7(10.9)$ & $57(89.1)$ & & $8(12.5)$ & $56(87.5)$ & \\
\hline Ki-67 labeling index, $\%(\text { mean } \pm \mathrm{SD})^{\mathrm{a}}$ & 28.7 & $=26.7 \quad 13.4$ & \pm 13.8 & $<0.0012$ & $6 \pm 26.513 .4$ & \pm 13.9 & $<0.001$ \\
\hline$<14, \mathrm{n}(\%)$ & 301 & $31(10.3)$ & $270(89.7)$ & $<0.001$ & $34(11.3)$ & $267(88.7)$ & $<0.001$ \\
\hline$\geq 14, \mathrm{n}(\%)$ & 181 & $42(23.2)$ & $139(76.8)$ & & $43(23.8)$ & $138(76.2)$ & \\
\hline Neoadjuvant chemotherapy, n (\%) & & & & & & & \\
\hline Yes & 31 & $4(12.9)$ & $27(87.1)$ & 0.719 & $4(12.9)$ & $27(87.1)$ & 0.629 \\
\hline No & 451 & $69(15.3)$ & $382(84.7)$ & & $73(16.2)$ & $378(83.8)$ & \\
\hline Subtype, n (\%) & & & & & & & \\
\hline Luminal type & 343 & $35(10.2)$ & $308(89.8)$ & $<0.001$ & $36(10.5)$ & $307(89.5)$ & $<0.001$ \\
\hline Luminal HER2 type & 31 & $1(3.2)$ & $30(96.8)$ & & $1(3.2)$ & $30(96.8)$ & \\
\hline HER2 type & 33 & $6(18.2)$ & $27(81.8)$ & & $7(21.2)$ & $26(78.8)$ & \\
\hline TNBC type & 75 & $31(41.3)$ & $44(58.7)$ & & $33(44.0)$ & $42(56.0)$ & \\
\hline
\end{tabular}

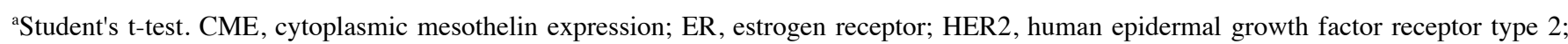
Ly, lymphatic invasion; MME, membrane mesothelin expression; NG, nuclear grade; PgR, progesterone receptor; SD, standard deviation; TNBC, triple-negative breast cancer; $\mathrm{V}$, vascular invasion. 
A

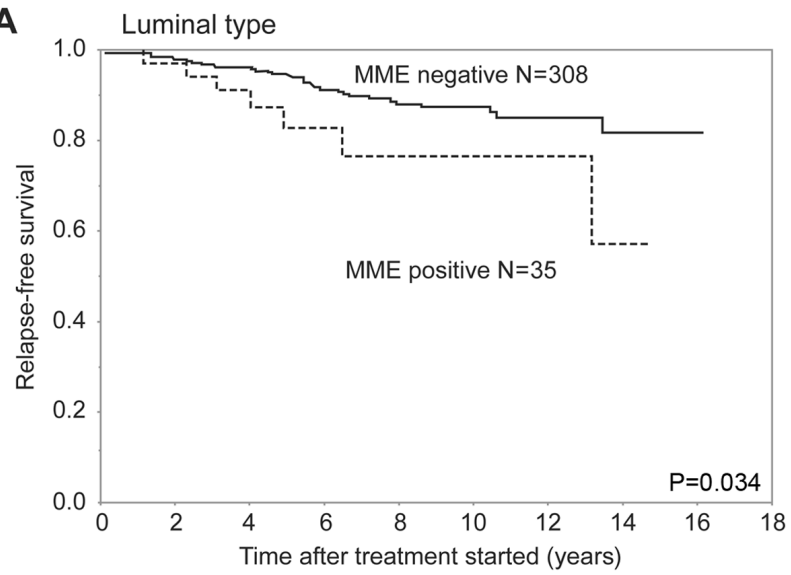

B

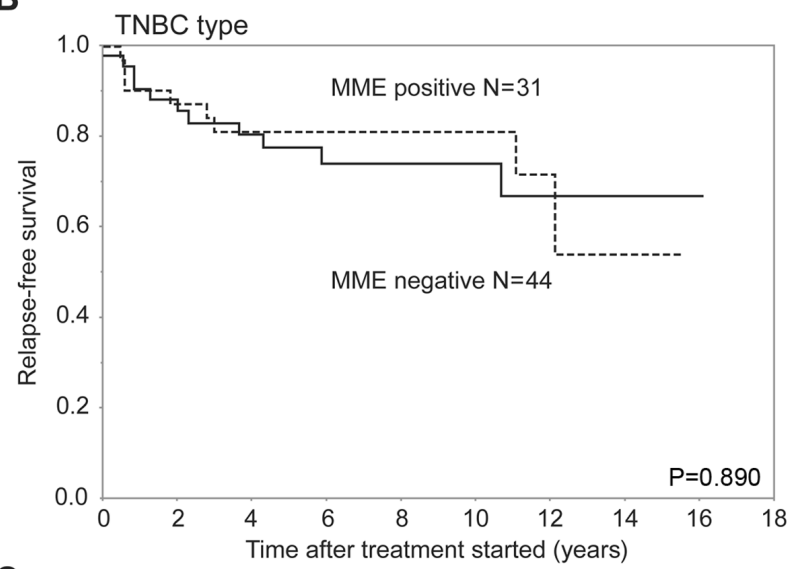

C

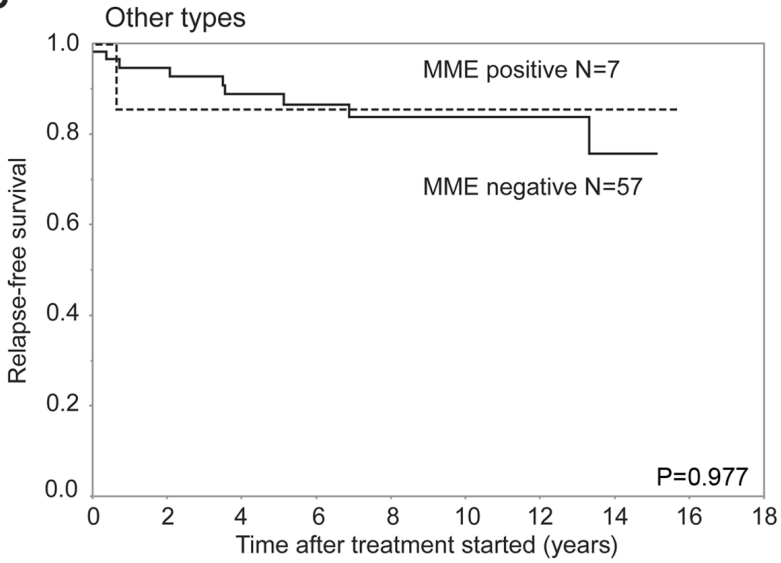

Figure 4. RFS for patients with each subtype of breast cancer after surgical therapy, stratified by the MME status. (A) Luminal type, (B) TNBC type and $(\mathrm{C})$ other types. MME in the luminal subtype was associated with RFS $(\mathrm{P}=0.034)$ but this was not the case for MME in the TNBC subtype and other types $(\mathrm{P}=0.890$ and $\mathrm{P}=0.977$, respectively). MME, membrane mesothelin expression; RFS, relapse-free survival; TNBC, triple-negative breast cancer.

agreement with the results of our study $(12-14,19)$. TNBC has a relatively higher relapse rate and worse OS rates than the other subtypes of breast cancer (20). Moreover, since there are few effective therapies that can improve the prognosis of TNBC patients, mesothelin has been researched as a potential candidate for targeted therapies. However, whether ME correlates with survival outcomes in TNBC remains unclear (12).

However, there were few studies on the clinicopathological implications of ME in the luminal type, which comprises $60-70 \%$ of all breast cancers. In the luminal type, the frequency

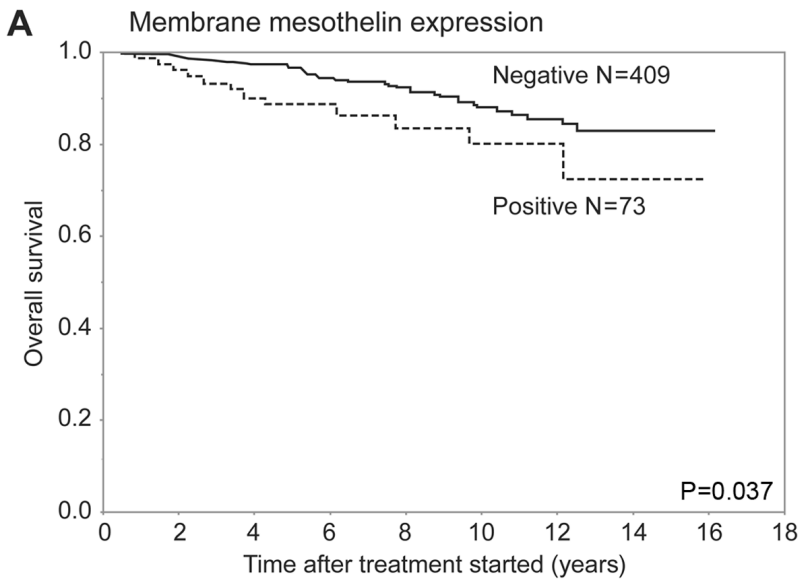

B

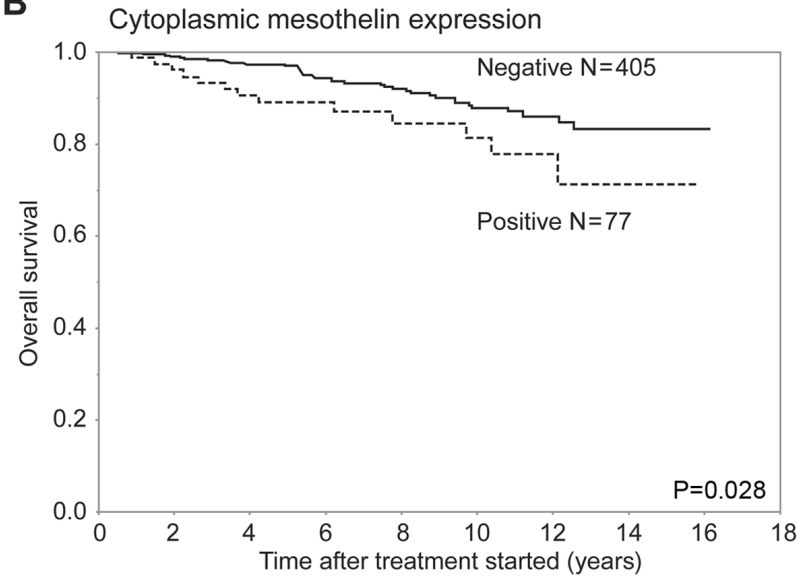

Figure 5. Overall survival curves for patients with breast cancer according to subtype after surgical therapy, stratified by the mesothelin expression status. (A) Membrane mesothelin expression. (B) Cytoplasmic mesothelin expression. Both membrane and cytoplasmic mesothelin expression-positive groups exhibited significantly less favorable outcomes than the membrane and cytoplasmic mesothelin expression-negative groups, respectively $(\mathrm{P}=0.037$ and $\mathrm{P}=0.028$, respectively).

of ME-positivity was lower than that of TNBC (10.2 vs. 41.3\%); however, MME-positivity was associated with a lower RFS rate, and consequently, MME might be useful as a biomarker to predict poor prognosis in luminal type breast cancer. In this group, Cox's multivariate analysis indicated that $\mathrm{pT}$ and $\mathrm{pN}$ were independent prognostic factors, whereas MME was not, likely because it was strongly related to biological factors, such as negative ER, negative PgR, a higher $\mathrm{Ki}-67 \mathrm{LI}$, and a higher $\mathrm{NG}$, and not to anatomical factors, such as $\mathrm{pT}$ and $\mathrm{pN}$. These results suggest that MME was not superior to $\mathrm{pT}$ and $\mathrm{pN}$ as a prognostic factor. ME was defined positive when the percentage of positive cells was $\geq 1 \%$ of tumor cells in this study. If we had defined ME-positivity more strictly, MME could have become an independent prognostic factor. Therefore, additional studies are necessary to determine whether ME can be used as a powerful prognostic factor.

The biological function of mesothelin remains unclear. Recent studies have suggested that overexpression of mesothelin increased cell proliferation and migration $(7,21)$. Moreover, it has also been suggested that mesothelin can elicit cytotoxic T lymphocyte (CTL) responses, and could efficiently activate CTL to lyse human tumors. Previous studies have shown that response to chemotherapy was 
Table III. Cox's univariate and multivariate analysis including clinicopathological parameters and mesothelin expression of recurrence-free survival in 482 patients with breast cancer.

\begin{tabular}{|c|c|c|c|c|}
\hline \multirow[b]{2}{*}{ Parameter } & \multicolumn{2}{|c|}{ Univariate } & \multicolumn{2}{|c|}{ Multivariate } \\
\hline & $\mathrm{HR}(95 \% \mathrm{CI})$ & P-value & $\mathrm{HR}(95 \% \mathrm{CI})$ & P-value \\
\hline \multicolumn{5}{|l|}{ pT } \\
\hline Tis, T1 & 1 & \multirow[t]{2}{*}{$<0.001$} & 1 & \multirow[t]{2}{*}{0.003} \\
\hline $\mathrm{T} 2, \mathrm{~T} 3$ & $3.64(2.19-6.32)$ & & $2.27(1.31-4.08)$ & \\
\hline \multicolumn{5}{|l|}{$\mathrm{pN}$} \\
\hline Negative & 1 & \multirow[t]{2}{*}{$<0.001$} & 1 & \multirow[t]{2}{*}{0.002} \\
\hline Positive & $3.76(2.30-6.35)$ & & $2.78(1.61-4.84)$ & \\
\hline \multicolumn{5}{|l|}{ NG } \\
\hline 1,2 & 1 & \multirow[t]{2}{*}{$<0.001$} & 1 & \multirow[t]{2}{*}{0.471} \\
\hline 3 & $2.26(1.40-3.73)$ & & $1.04(0.57-1.92)$ & \\
\hline \multicolumn{5}{|l|}{ Ly } \\
\hline Negative & 1 & \multirow[t]{2}{*}{0.002} & 1 & \multirow[t]{2}{*}{0.646} \\
\hline Positive & $2.32(1.34-4.27)$ & & $1.16(0.63-2.22)$ & \\
\hline \multicolumn{5}{|l|}{$\mathrm{V}$} \\
\hline Negative & 1 & \multirow[t]{2}{*}{0.003} & 1 & \multirow[t]{2}{*}{0.066} \\
\hline Positive & $2.05(1.28-3.30)$ & & $1.59(0.97-2.60)$ & \\
\hline \multicolumn{5}{|l|}{ ER } \\
\hline Negative & 1 & \multirow[t]{2}{*}{0.003} & 1 & \multirow[t]{2}{*}{0.497} \\
\hline Positive & $0.47(0.29-0.77)$ & & $0.72(0.35-1.68)$ & \\
\hline \multicolumn{5}{|l|}{$\operatorname{PgR}$} \\
\hline Negative & 1 & \multirow[t]{2}{*}{0.007} & 1 & \multirow[t]{2}{*}{0.412} \\
\hline Positive & $0.52(0.32-0.84)$ & & $0.72(0.35-1.61)$ & \\
\hline \multicolumn{5}{|c|}{ Ki-67 labeling index, $\%$} \\
\hline$<14$ & 1 & \multirow[t]{2}{*}{0.035} & 1 & \multirow[t]{2}{*}{0.374} \\
\hline$\geq 14$ & $1.68(1.04-2.69)$ & & $1.26(0.75-2.10)$ & \\
\hline \multicolumn{5}{|l|}{ MME } \\
\hline Negative & 1 & \multirow[t]{2}{*}{0.040} & 1 & \multirow[t]{2}{*}{0.659} \\
\hline Positive & $1.86(1.03-3.17)$ & & $1.11(0.57-2.07)$ & \\
\hline \multicolumn{5}{|l|}{ CME } \\
\hline Negative & 1 & 0.075 & & \\
\hline Positive & $1.71(0.94-2.91)$ & & & \\
\hline
\end{tabular}

CI, confidence interval; CME, cytoplasmic mesothelin expression; ER, estrogen receptor; MME, membrane mesothelin expression; HR, hazard ratio; Ly, lymphatic invasion; NG, nuclear grade; PgR, progesterone receptor; V, vascular invasion.

improved in patients with pancreatic cancer and other solid cancers using amatuximab, a chimeric monoclonal antibody that targets mesothelin $(22,23)$. TNBC is considered a good target of immunotherapy, and Tchou et al (14) reported that genetically modified T-cells expressing a chimeric antibody receptor (CAR) specific for mesothelin (mesoCAR T-cells) had high anti-tumor cytotoxicity. In the present study, we showed that the target for molecular target therapy could be expanded to the luminal type.

We demonstrated that MME-positivity was significantly associated with RFS and that CME-positive patients had relatively worse RFS. Both MME and CME are significantly related to OS, and previous studies have shown that MME-positivity was a poorer prognostic factor than CME in various cancer types $(4,8-10,21)$. Furthermore, Kawamata et al (21) presumed that mesothelin in the cytoplasm was in the $71 \mathrm{kDa}$ precursor form and might behave in a dominant-negative manner as a tumor suppressor in extrahepatic bile duct cancer. In this study, there were only four cases of cytoplasmic-only ME, and additional studies in a greater number of cases are required to prove this hypothesis in breast cancer.

In conclusion, we suggest that MME-positivity in breast cancer, especially in luminal type, is associated with poorer clinical outcomes. The clinical utility of the immunohistochemical examination of ME in surgically resected tumor specimens is expected to be useful for prognostication and decision making with regards to further treatment procedures after surgical therapy in breast cancer patients. 
Table IV. Cox's univariate and multivariate analysis including clinicopathological parameters and mesothelin expression of recurrence-free survival in 343 patients with luminal type breast cancer.

\begin{tabular}{|c|c|c|c|c|}
\hline \multirow[b]{2}{*}{ Parameter } & \multicolumn{2}{|c|}{ Univariate } & \multicolumn{2}{|c|}{ Multivariate } \\
\hline & HR (95\% CI) & $\mathrm{P}$-value & HR (95\% CI) & P-value \\
\hline \multicolumn{5}{|l|}{ pT } \\
\hline Tis, $\mathrm{T} 1$ & 1 & $<0.001$ & 1 & 0.011 \\
\hline $\mathrm{T} 2, \mathrm{~T} 3$ & $4.82(2.45-10.35)$ & & $2.58(1.24-5.79)$ & \\
\hline \multicolumn{5}{|l|}{$\mathrm{pN}$} \\
\hline Negative & 1 & $<0.001$ & 1 & $<0.001$ \\
\hline Positive & $6.58(3.26-14.71)$ & & $4.74(2.27-10.91)$ & \\
\hline \multicolumn{5}{|l|}{ NG } \\
\hline 1,2 & 1 & 0.003 & 1 & 0.185 \\
\hline 3 & $2.62(1.41-4.86)$ & & $1.55(0.81-2.98)$ & \\
\hline \multicolumn{5}{|l|}{ Ly } \\
\hline Negative & 1 & 0.024 & 1 & 0.923 \\
\hline Positive & $2.18(1.10-4.71)$ & & $1.04(0.51-2.27)$ & \\
\hline \multicolumn{5}{|l|}{$\mathrm{V}$} \\
\hline Negative & 1 & 0.005 & 1 & 0.113 \\
\hline Positive & $2.45(1.32-4.58)$ & & $1.68(0.88-3.21)$ & \\
\hline \multicolumn{5}{|c|}{ Ki-67 labeling index, $\%$} \\
\hline$<14$ & 1 & 0.113 & & \\
\hline$\geq 14$ & $1.72(0.87-3.25)$ & & & \\
\hline \multicolumn{5}{|l|}{ MME } \\
\hline Negative & 1 & 0.062 & & \\
\hline Positive & $2.35(0.95-5.02)$ & & & \\
\hline \multicolumn{5}{|l|}{ CME } \\
\hline Negative & 1 & 0.067 & & \\
\hline Positive & $2.31(0.94-4.93)$ & & & \\
\hline
\end{tabular}

CI, confidence interval; CME, cytoplasmic mesothelin expression; HER2, human epidermal growth factor receptor type 2; HR, hazard ratio; Ly, lymphatic invasion; NG, nuclear grade; MME, membrane mesothelin expression; V, vascular invasion.

\section{Acknowledgements}

Not applicable.

\section{Funding}

Data extraction and analysis were supported by JSPS KAKENHI (grant no. JP 18K07340). JSPS did not influence the study design, data collection, data analysis, data interpretation or writing of the manuscript.

\section{Availability of data and materials}

The datasets used and/or analyzed during the current study are available from the corresponding author on reasonable request.

\section{Authors' contributions}

TK, TY, MFK, YI, YT and TSh collected the data and assisted in data analysis. YM, TI, ES and KS contributed to interpretation of data and manuscript preparation. TSu analyzed the data and wrote the original draft. YY, TE and HT conceived the study and reviewed and revised the manuscript. JY and YK made substantial contributions to the conception and design. HU made substantial contributions to analysis and interpretation of data. JY, YK and HU provided supervision of the manuscript. All authors read and approved the final manuscript.

\section{Ethics approval and consent to participate}

The present study was performed in accordance with the Declaration of Helsinki, and was approved by the Institutional Review Board of the National Defense Medical College (registration no. 3003). All patients agreed to participate in the present study, and written informed consent was obtained from all patients.

\section{Patient consent for publication}

Not applicable. 


\section{Competing interests}

The authors declare that they have no competing interests.

\section{References}

1. Chang K, Pastan I and Willingham MC: Isolation and characterization of a monoclonal antibody, $\mathrm{K} 1$, reactive with ovarian cancers and normal mesothelium. Int J Cancer 50: 373-381, 1992.

2. Argani P, Iacobuzio-Donahue C, Ryu B, Rosty C, Goggins M Wilentz RE, Murugesan SR, Leach SD, Jaffee E, Yeo CJ, et al: Mesothelin is overexpressed in the vast majority of ductal adenocarcinomas of the pancreas: Identification of a new pancreatic cancer marker by serial analysis of gene expression (SAGE). Clin Cancer Res 7: 3862-3868, 2001.

3. Ordonez NG: Value of mesothelin immunostaining in the diagnosis of mesothelioma. Mod Pathol 16: 192-197, 2003.

4. Einama T, Kamachi H, Nishihara H, Homma S, Kanno H, Takahashi K, Sasaki A, Tahara M, Okada K, Muraoka S, et al: Co-expression of mesothelin and CA125 correlates with unfavorable patient outcome in pancreatic ductal adenocarcinoma. Pancreas 40: 1276-1282, 2011.

5. Chang K and Pastan I: Molecular cloning of mesothelin, a differentiation antigen present on mesothelium, mesotheliomas, and ovarian cancers. Proc Natl Acad Sci USA 93: 136-140, 1996.

6. Hassan R, Bera T and Pastan I: Mesothelin: A new target for immunotherapy. Clin Cancer Res 10: 3937-3942, 2004.

7. Li M, Bharadwaj U, Zhang R, Zhang S, Mu H, Fisher WE, Brunicardi FC, Chen S and Yao Q: Mesothelin is a malignant factor and therapeutic vaccine target for pancreatic cancer. Mol Cancer Ther 7: 286-296, 2008

8. Shiraishi T, Shinto E, Mochizuki S, Tsuda H, Kajiwara Y, Okamoto K, Einama T, Hase K and Ueno H: Mesothelin expression has prognostic value in stage II/III colorectal cancer. Virchows Arch 474: 297-307, 2019.

9. Einama T, Homma S, Kamachi H, Kawamat F, Takahashi K, Takahashi N, Taniguchi M, Kamiyama T, Furukawa H, Matsuno Y, et al: Luminal membrane expression of mesothelin is a prominent poor prognostic factor for gastric cancer. Br J Cancer 107: 137-142, 2012.

10. Shiraishi T, Shinto E, Nearchou IP, Tsuda H, Kajiwara Y, Einama T, Caie PD, Kishi Y and Ueno H: Prognostic significance of mesothelin expression in colorectal cancer disclosed by area-specific four-point tissue microarrays. Virchows Arch: Feb 27, 2020 (Epub ahead of print). doi: 10.1007/s00428-020-02775-y.

11. Wang L, Niu Z, Zhang L, Liu X, Wang X, Li F and Wang Y: Clinicopathological significance of mesothelin expression in invasive breast cancer. J Int Med Res 40: 909-916, 2012.

12. Parinyanitikul N, Blumenschein GR, Wu Y, Lei X, Chavez-Macgregor M, Smart M and Gonzalez-Angulo AM: Mesothelin expression and survival outcomes in triple receptor negative breast cancer. Clin Breast Cancer 13: 378-384, 2013.

13. Bayoglu IV, Kucukzeybek BB, Kucukzeybek Y, Varol U, Yildiz I, Alacacioglu A, Akyol M, Demir L, Dirican A and Yildiz Y: Prognostic value of mesothelin expression in patients with triple negative and HER2-positive breast cancers. Biomed Pharmacother 70: 190-195, 2015.
14. Tchou J, Wang LC, Selven B, Zhang H, Conejo-Garcia J, Borghaei H, Kalos M, Vondeheide RH, Albelda SM, June $\mathrm{CH}$ and Zhang PJ: Mesothelin, a novel immunotherapy target for triple negative breast cancer. Breast Cancer Res Treat 133: 799-804, 2012.

15. Tsuda H, Akiyama F, Kurosumi M, Sakamoto G and Watanabe T: Establishment of histological criteria for high-risk node-negative breast carcinoma for a multi-institutional randomized clinical trial of adjuvant therapy. Japan National Surgical Adjuvant Study of Breast Cancer (NSAS-BC) pathology section. Jpn J Clin Oncol 28: 486-491, 1998.

16. Dowsett M, Nielsen TO, A'Hern R, Bartlett J, Coombes RC, Cuzick J, Ellis M, Henry NL, Hugh JC, Lively T, et al: Assessment of Ki67 in breast cancer: Recommendations from the international Ki67 in Breast Cancer working group. J Natl Cancer Inst 103: 1656-1664, 2011.

17. Cheang MC, Chia SK, Voduc D, Gao D, Leung S, Snider J, Watson M, Davies S, Bernard PS, Parker JS, et al: Ki67 index, HER2 status, and prognosis of patients with luminal B breast cancer. J Natl Cancer Inst 101: 736-750, 2009.

18. Curigliano G, Burstein HJ, Winer EP, Gnant M, Dubsky P,Loibl S, Colleoni M, Regan MM, Piccart-Gebhart M, Senn HJ, et al: De-escalating and escalating treatments for early-stage breast cancer: The St. Gallen international expert consensus conference on the primary therapy of early breast cancer 2017 . Ann Oncol 30: 1181, 2019.

19. Wang M, Li A, Sun G, Mbuagbaw L, Reid S, Lovrics PJ and Thabane L: Association between mesothelin expression and survival outcomes in patients with triple-negative breast cancer: A protocol for a systematic review. Syst Rev 5: 133, 2016.

20. Tan AR and Swain SM: Therapeutic strategies for triple-negative breast cancer. Cancer J 14: 343-351, 2008.

21. Kawamata F, Kamachi H, Einama T, Homma S, Tahara M, Miyazaki M, Tanaka S, Kamiyama T, Nishihara H, Taketomi A and Todo S: Intracellular localization of mesothelin predicts patient prognosis of extrahepatic bile duct cancer. Int J Oncol 41: 2109-2118, 2012

22. Mizukami T, Kamachi H, Fujii Y, Matsuzawa F, Einama T, Kawamata F, Kobayashi N, Hatanaka Y and Taketomi A: The anti-mesothelin monoclonal antibody amatuximab enhances the anti-tumor effect of gemcitabine against mesothelin-high expressing pancreatic cancer cells in a peritoneal metastasis mouse model. Oncotarget 9: 33844-33852, 2018.

23. Fujisaka Y, Kurata T, Tanaka K, Kudo T, Okamoto K, Tsurutani J, Kaneda H, Okamoto I, Namiki M, Kitamura C and Nakagawa K: Phase I study of amatuximab, a novel monoclonal antibody to mesothelin, in Japanese patients with advanced solid tumors. Invest New Drugs 33: 380-388, 2015.

This work is licensed under a Creative Commons Attribution-NonCommercial-NoDerivatives 4.0 International (CC BY-NC-ND 4.0) License. 